\title{
Study of cutting properties and wear pattern of carbide tools with comprehensive chemical-thermal treatment and nano-structured/gradient wear-resistant coatings
}

\author{
Sergey N. Grigoriev ${ }^{\mathrm{a}}$ \\ Moscow State University of Technology "STANKIN", 1 Vadkovsky per., Moscow GSP-4, 127994, Russian Federation
}

Received 16 September 2016, Accepted 28 November 2016

\begin{abstract}
The paper is focused on the challenges to improve the life of carbide cutting tools through the deposition of a modifying composite wear-resistant multi-phase complex on the working surface, formed on the basis of the developed comprehensive surface treatment. The developed wear-resistant complex contains complex carbides of hafnium, formed by preliminary alloying of the surface of the carbide, and multi-layered composite coatings on the basis of system titanium aluminum nitride $((\mathrm{TiAl}) \mathrm{N})$, obtained by subsequent deposition. The paper includes studies of the complex structure of the wear-resistant complex to be deposited on the surface of the cemented carbide and studies of the mechanism of wear and cutting properties of carbide tools with the developed comprehensive treatment. The studies have shown that the application of the comprehensive surface treatment can increase the life of carbide tools by 3-3.5 times in comparison with the life of an uncoated tool and by two times in comparison with the life of carbide tools coated with standard titanium nitride ( $\mathrm{TiN})$.
\end{abstract}

Key words: Tool life / carbide / cutting tool / wear-resistant coating / surface modification

\section{Introduction}

One of the key challenges of modern engineering production is to increase the efficiency of the technological processes of cutting while improving the reliability of cutting tools. Improvement of the basic performance of tools made of carbide, which is the most widely used tool material in modern material-processing industries, is an extremely important part of the general challenge. To significantly increase their cutting properties, the development and application of a comprehensive surface treatment for carbide tools includes a preliminary surface treatment in combination with subsequent depositions of multi-layered nanoscale wear-resistant coating and is an effective method to solve this challenge.

The main purposes of the preliminary treatment of the carbide substrate are the following:

- Creation of a transition zone in the surface layers of the carbide substrate, characterized by crystalchemical and physico-mechanical properties similar to the corresponding properties of the deposited coating;

- Reduction of the roughness of the carbide substrate surface;

\footnotetext{
${ }^{a}$ Corresponding author: science@stankin.ru
}

- Blocking elements of carbide cobalt binder, which are located in the surface layer;

- Creation of structural off-balance states in the surface layers of the carbide substrate through the synthesis of refractory compounds that increase the surface hardness and wear resistance;

- Reduction of the free carbon content as well as the non-stoichiometric tungsten carbide (WC) phases, such as $\alpha-\mathrm{W}_{2} \mathrm{C}$, phase transformation from hexagonal $\alpha$-WC to cubic $\beta$ - $\mathrm{WC}_{1-\mathrm{x}}$, and the increase of the content of the $\varepsilon$-phase of $\mathrm{Co}_{3} \mathrm{~W}_{3} \mathrm{C}$ ternary phase and $\gamma-\mathrm{WC}$;

- Reduction in the level of compressive residual stresses in the surface layers of the carbide substrate.

It should be noted that, at present, for preliminary treatment of the carbide substrate, several different methods are used, such as oxidizing flame in combination with acid treatment $[1,2]$, laser treatment, one-pot non-vapor deposition, polishing and micro- and glass-blasting, shot peening, and high-intensity pulsed ion beam irradiation.

In particular, papers [3,4] considered the methods for treatment of carbide substrate before the deposition of diamond coating, including oxidizing oxygen/acetylene flame at $1000{ }^{\circ} \mathrm{C}$, scratching with diamond particles or their mixture with iron in an ultrasonic bath, and seeding 
with a nanometer diamond colloidal suspension in combination with acid treatment.

The oxidizing flame was found to produce fine-grained $\mathrm{W}, \mathrm{W}_{2} \mathrm{C}$, and $\mathrm{WO}_{2}$, resulting in an increased diamond particle density and lower coating roughness, leading to a relatively smooth and adherent diamond coating. However, the products of WC oxidation were detectable only if cobalt (Co) had been removed from the substrate surface prior to the action of the flame. Otherwise, compounds of Co with phosphorus and oxygen were formed, making a skin on the surface, which hindered the action of the flame on the WC. The acid treatment was found to remove Co effectively from the surface.

The authors of paper [3] focused on the comparison of the efficiency of the application of different reagents for Co removal by acid etching on the substrate in order to improve the adhesion of the hot filament-chemical vapor deposition (HF-CVD) diamond coating with the substrate. The diamond coating has been found to show highest adhesion when deposited on $\mathrm{HNO}_{3}+\mathrm{HCl}+\mathrm{H}_{2} \mathrm{O}$ (1:1:1) treated carbide substrate. In addition, the surface roughness of the etched surface appeared to be highest under this treatment.

For the above purposes, the study may also use a number of methods dedicated to the combination of laser pre-treatment followed by deposition of a wearresistant coating. In particular, the paper focuses on the complex treatment of carbide substrate, including pretreatment by pulsed copper HyBrID laser before deposition of TiCN $/ \mathrm{Al}_{2} \mathrm{O}_{3} / \mathrm{TiN}$ coating by the medium temperature (MT)-CVD process. The laser process was found to produce WC phases, such as $\beta-\mathrm{WC}_{1-\mathrm{x}}$ and $\alpha-\mathrm{W}_{2} \mathrm{C}$, that are less carbon non-stoichiometric. The application of laser pre-treatment has significantly increased the adhesion between the coating and substrate. In paper [5], the substrates were textured in four different intensities with a neodymium-doped yttrium aluminum garnet (Nd:YAG) laser and then coated with a physical vapor deposition (PVD) TiAlN film. The PVD coated laser-textured tool showed better performance in the indentation and turning tests than the standard tools. A comparative evaluation of tool-wear mechanisms indicated that texturing did not change the wear mechanisms but altered their importance to tool wear. Additionally, the chemical modification of the carbide grains due to laser heating might be responsible for an enhanced adhesion between the coating and substrate.

We consider the one-pot non-vapor deposition method, which provides an opportunity to implement the coating process in combination with the preparation of the substrate. A Co capping phenomenon exists on the uncoated cemented carbide, which is due to the Co migration of liquid Co from the interior to the surface during vacuum sintering. A coating of aluminum oxide $\left(\mathrm{Al}_{2} \mathrm{O}_{3}\right)$ was deposited. After coating, the surface of the cemented carbide is covered with a layer of $\sim 0.5 \mu \mathrm{m} \mathrm{Al} \mathrm{Al}_{2} \mathrm{O}_{3}$ fine grains and $\sim 2 \mu \mathrm{m}$ WC particles. The dip-coating process leads to the loss of carbon, and only a trace of $\mathrm{Co}_{3} \mathrm{~W}_{3} \mathrm{C}$ ternary phase exists on the surface. After $\mathrm{Al}_{2} \mathrm{O}_{3}$ coat- ing, the hardness increases and the transverse rupture strength decreases, which is attributed to the existence of $\mathrm{W}_{3} \mathrm{Co}_{3} \mathrm{C}$ on the surface. Though $\mathrm{Al}_{2} \mathrm{O}_{3}$-based coating can be achieved using this one-pot method, the surface has high roughness and low thickness. Thus, the authors of paper [6] concluded that, at present, the offered method cannot be used for deposition of coatings on metal-cutting tools.

In paper [7], the wear behavior of coated cementedcarbide inserts with various substrate and coating-surface mechanical treatments were investigated experimentally in milling and analytically through a finite-element method simulation of the cutting process. The treatments were polishing and micro- and glass-blasting at various pressures. The analytically supported experimental results revealed that substrate-surface micro-blasting at high pressure contributes to enhanced coating adhesion properties and leads to an increased milling performance of cutting inserts. On the other hand, substrate polishing worsens the adhesion strength as well as the tool cutting performance.

Paper [8] focuses on pre-treatment of carbide substrate by shot peening. The results show that the compressive residual stresses in $\mathrm{WC}$ and Co phase increase by $48 \%$ and $70 \%$, respectively, after shot peening. The surface topography and dislocation densities are improved substantially, while the domain size decreases dramatically. Compared with the unaffected region, the microstrain becomes severe in the affected region, and the microhardness improves greatly and reaches its maximum in a nano-crystalline layer formed at the top surface of the specimen, indicating that it is not subjected to the inverse Hall-Petch effect.

Paper [9] considers pre-treatment of carbide substrate by high-intensity pulsed ion beam irradiation. The results show that the high-intensity pulsed ion beam irradiation induces rapid remelting and selective ablation of the Co binder phase on the surface of the WC-Co cemented carbides, resulting in the phase transformation from hexagonal $\alpha$-WC to cubic $\beta$-WC $\mathrm{WC}_{1-\mathrm{x}}$ in the irradiated surface layer, forming a remelting and ablation morphology with dome-shaped projection.

The challenges of the directed modifications of the surface layer for substrates of high-speed steel (HSS) and carbide were also considered in papers [10-12]. In particular, the papers focused on the challenges of nitridation of the surface layer of HSS as well as the alloying of carbide substrate NbHfTi.

The challenges of the deposition of multi-layered composite nano-structured coatings on carbide substrate pre-treated using different methods were considered in papers [13-17].

A series of studies show that pre-treatment of carbide substrate using various methods before the deposition of the wear-resistant coating can further improve the life and reliability of carbide metal-cutting tools.

Thus, the analysis of the research papers referred to above indicates a lack of universal methods for the pretreatment of surfaces of tools made of HSS and carbide. 
Such a method would contribute to the high adhesive strength of innovative multi-layered composite coatings and the high-efficiency operation of the cutting tools in machining operations for various materials, for which certain requirements for the surface are presented. In this context, the purpose of this paper is to develop an innovative method of the formation of wear-resistant complexes on the working surfaces of carbide tools to ensure a substantial increase in their cutting properties.

\section{Experimental details}

The methodology of these studies to develop a comprehensive surface treatment of carbide tools includes:

- Preliminary formation of thin films on the basis of composition $\mathrm{Nb}_{70} \mathrm{Hf}_{22} \mathrm{Ti}_{8}$ with thickness of $150-$ $250 \mathrm{~nm}$ using a magnetron system on samples of carbide substrates;

- Treatment of carbide samples with surface films $\mathrm{Nb}_{70} \mathrm{Hf}_{22} \mathrm{Ti}_{8}$ in the same process chamber under the influence of a wide series of pulses of a wideaperture low-energy high-current electron beam in order to synthesize a layer containing wear-resistant non-stoichiometric carbides with hcc structure.

The treatment took place in an RITM-SP unit in a vacuum chamber equipped with a source of low-energy high-current electron beams and two magnetron spraying systems. The unit ensures deposition of films of various materials on the surface of a workpiece, followed by the liquid-phase stirring of materials of film and substrate by intense pulsed electron beam [18].

Low-energy high-current electron beams are generated through acceleration in the double electric layer of the electrons from the cathode plasma generated through the explosive electrical emission. The application of this scheme provides a beam of microsecond duration with a current density of up to $10^{4} \mathrm{~A} / \mathrm{cm}^{2}$ and electron energy of $15-30 \mathrm{keV}$. The area of the one-time treatment of the target, which is equal to the diameter of the beam, can reach up to $80 \mathrm{~cm}^{2}$.

The treatment results in the change in the carbide phase structure and the formation of molten metal in the volume of more refractory particles. This results in a sharp increase in the phase contact area and an increase in the rate of carbide-formation reaction. Compounds are formed, such as $\gamma-\mathrm{WC}, \mathrm{TiC}, \mathrm{NbC}$, and $\mathrm{HfC}$, which are able to form non-stoichiometric structures, with a range of non-stoichiometry varying from 0.5 to 0.97 . Meanwhile, no surface decarburization occurs, and with the increase in the number of carbon vacancies, the covalent chemical bond in carbides transforms into a metal bond. In turn, that results in the improvement in plasticity and thermal conductivity of the surface layers of the substrate. Thus, alloying was performed with reaction-forming hafnium carbide in the composition of composite carbide on the carbide surface.

The multi-layered complex composite wear-resistant coating on the basis of system titanium aluminum nitride
$((\mathrm{TiAl}) \mathrm{N})$ was deposited in a unit Platit $\mathrm{Pi} 80$ using the technology LARC ${ }^{\circledR}$ (lateral rotating cathodes).

The microstructural tests of the carbide samples with comprehensive surface treatment were conducted with the use of a scanning electron microscope (SEM) FEI Quanta 600 FEG. The studies of chemical composition were conducted with the use of a raster electron microscope FEI Quanta 600 FEG. To perform X-ray microanalysis, the study used characteristic X-ray emission resulting from electron bombardment of a sample.

\section{Theoretical prerequisites}

The mechanical component of the intensity of adhesion $N_{M}$ highly depends on the hardness of the material (compound). When the hardness grows, dislocation mobility decreases sharply and the tendency of the first wearresistant layer of coating to adhere to the machined material decreases. In this context, it should be noted that, according to the phenomenological configuration model of substance (CMS), the highest hardness is typical for substances with prevailing SWASC $s p^{3}$, where covalent (or metal) bonds increase the stiffness of its crystal lattice. This provides very low mechanical compliance, hinders the mobility of dislocations and vacancies, and reduces the tendency of adhesion to the machined material.

Configurations $s^{2}, p^{6}$, which are energetically very stable and typical for nitrides of refractory metals of group IV and partly groups V and VI with high donor ability ( $\mathrm{Ti}, \mathrm{Zr}, \mathrm{Hf}, \mathrm{Nb}$, and $\mathrm{Cr}$ ), are characterized by crystal lattice with lower hardness. They also increase the resistance of compounds to mechanical activation.

In choosing the material for the wear-resistant layer of the multi-layered composite coating with the assumption of the prevailing influence of adhesion-fatigue processes on the wear of carbide tools, preference should be given to solid refractory compounds. These compounds contain a maximum amount of SWASCs of stable $s p^{3}$ configurations (materials with predominantly metallic or covalent bonds), $s^{2}, p^{6}$ configurations (materials with metallic or mixed bonds), and $d^{5}$ configurations (materials with covalent and ionic bonds).

To form the third adhesive layer of coating, preference was given to compounds with metallic bonds (such as Ti, $\mathrm{Zr}, \mathrm{Cr}, \mathrm{TiN}, \mathrm{CrN}$, etc.). To form the second intermediate layer, it is reasonable to use compounds with ionic bonds (such as $\mathrm{SiC}, \mathrm{Si}_{3} \mathrm{~N}_{4}, \mathrm{Al}_{2} \mathrm{O}_{3}$, AlN, etc.).

In addition to the determination of the compositions, the mechanical and physical-chemical properties of the coating layers, and the need to maximize the strength of adhesion, another important parameter of coating is its structure, which has a strong influence on the fatigue strength of the coating in general.

It is known from [19-21] that ultra-fine materials with enlarged grain boundaries, characterized by high toughness and resistance to "brittle" cracks, are able to more efficiently resist fracture under complex external influence. In this context, the development of coatings for tools 


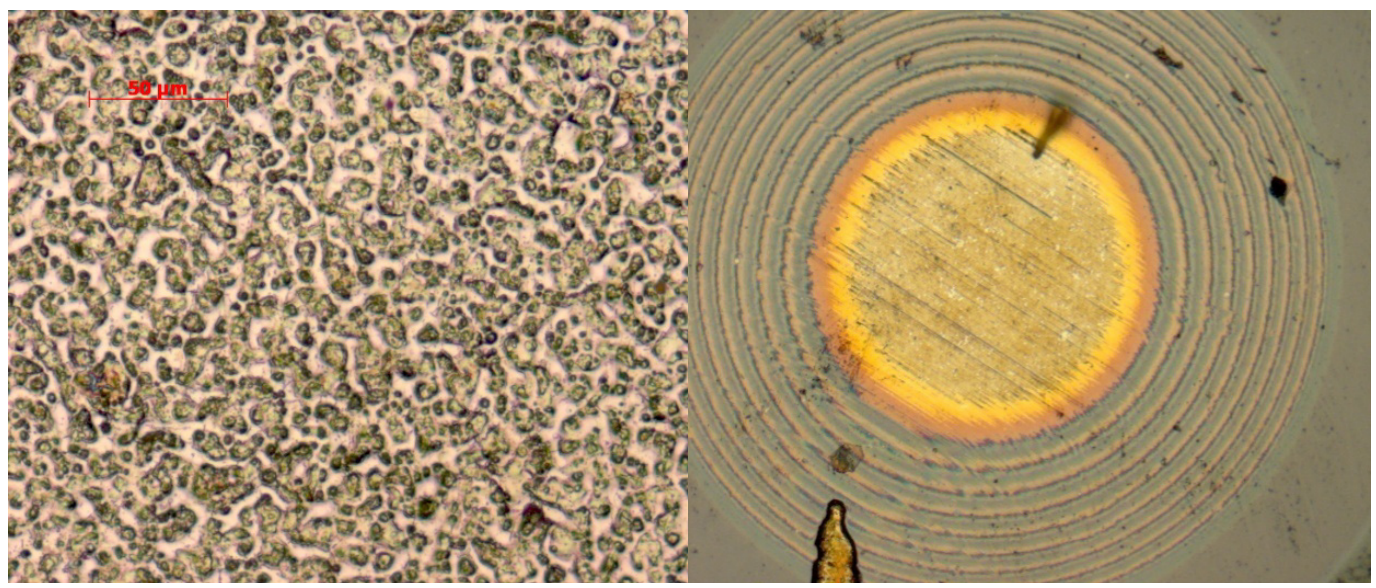

Fig. 1. Structure of the surface of a carbide substrate after micro-alloying with carbide NbHfTi (a) and the internal structure of the coating on a spherical thin section (b).

should be based on the architecture, characterized by a nano-sized structure and a multi-layered formation with an increased area of grain and interlayer boundaries with high resistance to fracture, particularly under conditions of alternating thermomechanical stresses. This concept of coating will allow a significant increase of its lifetime and prediction of a significant increase in time between failures for the cutting tool.

The increase of the area of grain and interlayer boundaries may be achieved through the formation of a nanocrystalline grain structure and a super multi-layered architecture with nanometer-thick sublayers of each coating layer. This causes quite a pronounced relation between the properties of the material and the nature of its macro- and micro-fractures (elastic, brittle, abrasive, adhesive-fatigue, chemical-oxidative, diffusive, etc.). The intensity of tool wear highly depends on the corresponding relation between the toughness and hardness of coating layers. Grain and interlayer boundaries are an area of intense dissipation of energy and deviation of cracks from the direction of motion, and partial or complete inhibition, which results in hardening of the material. On this basis, the use of multi-layered architecture of coatings provides an increase in the life of a carbide tool, especially under conditions of cyclic thermomechanical stresses. Moreover, grain boundaries, which contribute to the formation of grain size and the texture of the material, are able to effectively strengthen coatings. Examples of nanoscale composite coatings with three-layered architecture and nanoscale-thick sublayers in layers 1 and 2 are shown in Figures $1 \mathrm{~b}$ and $2 \mathrm{a}$.

\section{Results and discussion}

\subsection{Study of internal structure of wear-resistant complex modified layer multi-layered wear-resistant coating}

Due to the deposition on the tool surface of a thin layer of the carbide-forming elements $\mathrm{Nb}, \mathrm{Ti}$, and $\mathrm{Hf}$ prior to treatment by electron beam, it is possible to obtain a multi-phase carbide structure, outwardly resembling eutectic, through alloying and reaction of self-spreading high-temperature synthesis (Fig. 1a). Meanwhile, it is possible to avoid the accumulation of free carbon along the boundaries of the carbide grains and prevent surface cracking because of residual thermal stresses. As a result of the reaction of the self-spreading high-temperature synthesis, the outer layer is enriched with refractory carbide phases, which remain small and homogeneously distributed due to the extremely high cooling rate.

After treatment by electron beam, a multi-layered complex composite wear-resistant coating on the basis of system $(\mathrm{TiAl}) \mathrm{N}$, with a total thickness of about $10 \mu \mathrm{m}$, was deposited on the carbide substrate. The structure of the carbide substrate with a coating, studied on the spherical section with the use of a toolmaker's microscope (Fig. 1b) and on the transverse section with the use of a raster electron microscope (Fig. 2a), comprises the following four layers:

- Transition layer of the carbide substrate, formed by contact melting of tungsten carbide grains (with a thickness of about $1 \mu \mathrm{m})$;

- Adhesion layer of coating (with a thickness of about $0.5 \mu \mathrm{m})$;

- Inner transition layer of coating with a structure formed by sublayers with a thickness of about 150$300 \mathrm{~nm}$ (with a total thickness of the layer of about $5 \mu \mathrm{m})$;

- Outer wear-resistant layer with a gradient structure (with a total thickness of about $5 \mu \mathrm{m}$ );

The treatment by electron beam causes not only a modification of the structure of subsurface layers of the carbide substrate but also an occurrence of microparticles of carbide-forming elements embedded into its surface (Nb, Hf, and Ti) (see Figs. 2b and 2c). In turn, those embedded microparticles have a certain influence on the formation of the coating microstructure. 

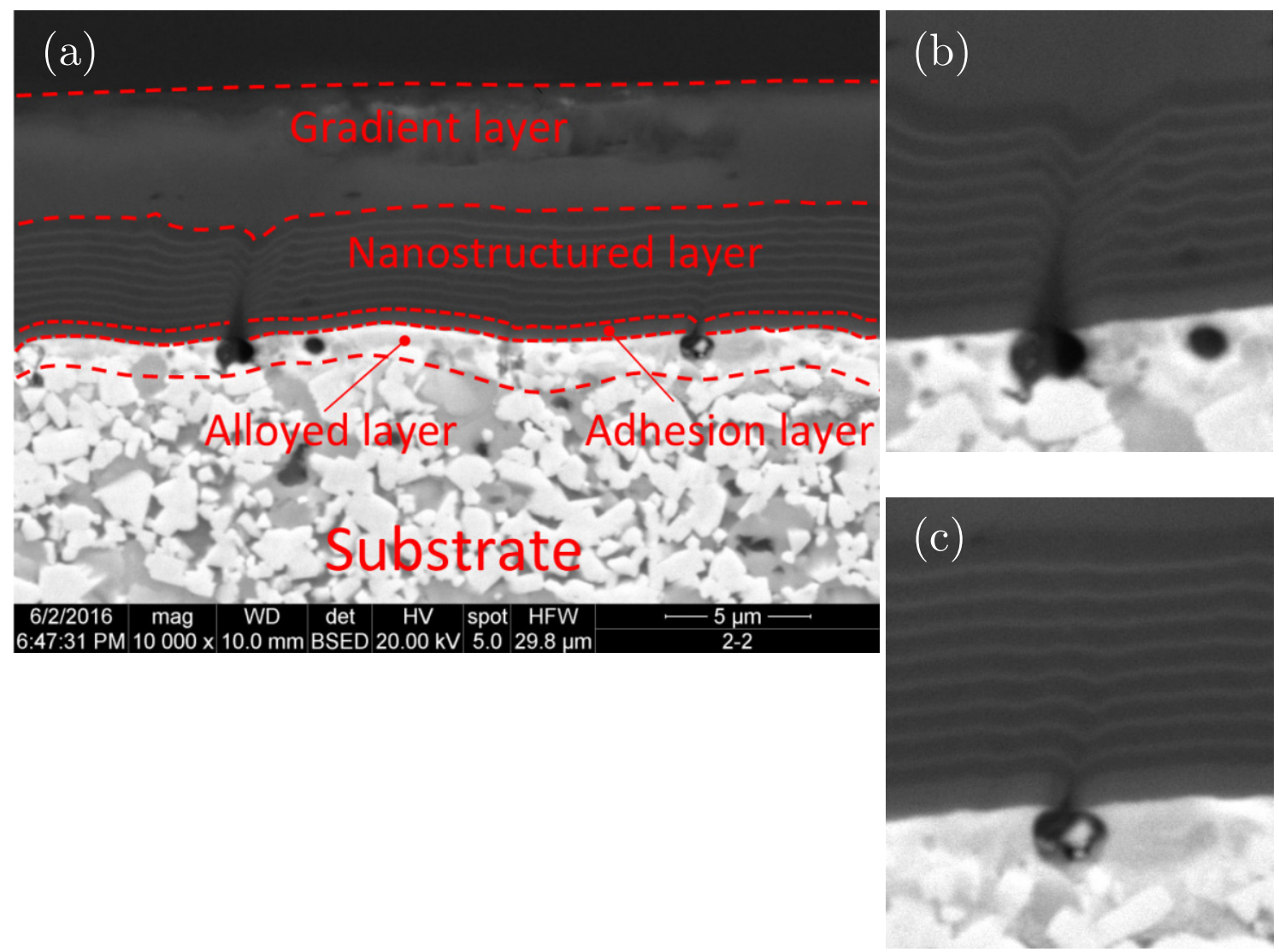

Fig. 2. Microstructure of the transverse section of the carbide substrate after treatment by electron beam and deposition of a multi-layered complex composite wear-resistant coating on the basis of system (TiAl)N (a), view of metal particles embedded into the substrate during alloying and their effect on the structure of the coating $(b, c)$.

\subsection{Study of cutting properties of carbide tools with the eveloped composite wear-resistant complex}

The study of cutting properties of the carbide tools with developed coatings was conducted on a lathe CU 500 MRD with longitudinal turning of steel C45 (HB 200). The study used cutters with mechanically fastened inserts made of carbide with square shape (SNUN ISO 1832:2012) and with the following geometric parameters of the cutting part: $\gamma=-8^{\circ}, \alpha=6^{\circ}, \chi=45^{\circ}, \lambda=0$, and $r=0.8 \mathrm{~mm}$. The study was carried out at the following cutting modes: $f=0.25 \mathrm{~mm} / \mathrm{rev}, a_{p}=1.0 \mathrm{~mm}$, and $v_{c}=200$ and $250 \mathrm{~m} / \mathrm{min}$.

Flank wear land $V B_{c}=0.45-0.5 \mathrm{~mm}$ was taken as a failure criterion. It was measured with a toolmaker's microscope MBS-10 as the arithmetic mean of four or five tests. The results were processed using parametric identification of the exponential stochastic multiplicative mathematical model by least squares method, using the formula (1):

$$
V B=C(1) v_{c}^{A(1,1)} T^{A(1,2)}
$$

Curves obtained by mathematical processing of the experimental data are shown in Figure 3.

The studies of cutting properties have shown that the life of the carbide tools with the developed comprehensive surface treatment exceeds the life of the test carbide tool by $3-3.5$ times and exceeds the life of a tool with standard coating TiN by two times. Meanwhile, the tool with the developed comprehensive treatment has shown an extremely high wear resistance during the first 30-35 min of cutting; however, the tool wear rate has subsequently increased quite strongly. The above specific feature of wear was particularly sharply manifested in testing at the cutting speed of $v_{c}=250 \mathrm{~m} / \mathrm{min}$ when, after $36 \mathrm{~min}$ of cutting, the tool wear rate increased sharply.

\subsection{Mechanisms of wear and failure of carbide tools with the developed wear-resistant complex}

Figure 4 shows the cross-cut sections of the contact cutting area of a carbide tool with developed comprehensive treatment. The tests revealed the clear flank wear land with the absence of a wear crater on the rake face. The tests also revealed the appearance of longitudinal and transverse cracks formed in the coating structure and the presence of particles of the machined material adherent to the flank face (a) and in the area adjacent to the cutting edge (b). Moreover, the study found considerably deep penetration of particles of the machined material in the area of carbide substrate chipping (b) and in the cracks in the system coating-substrate. 


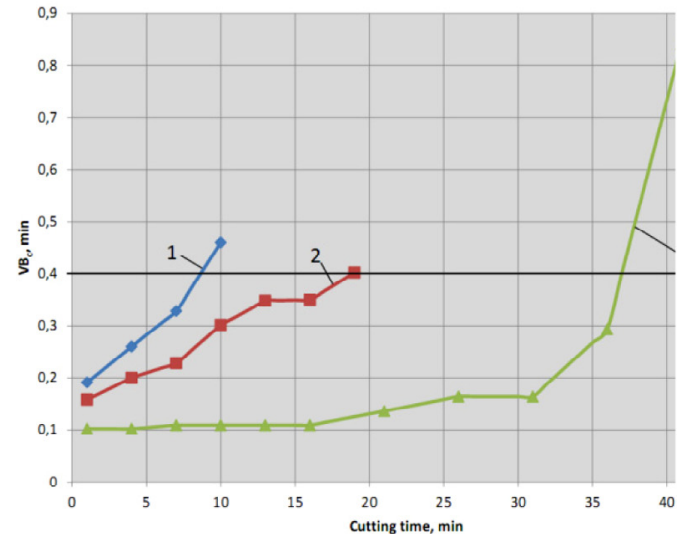

(a)

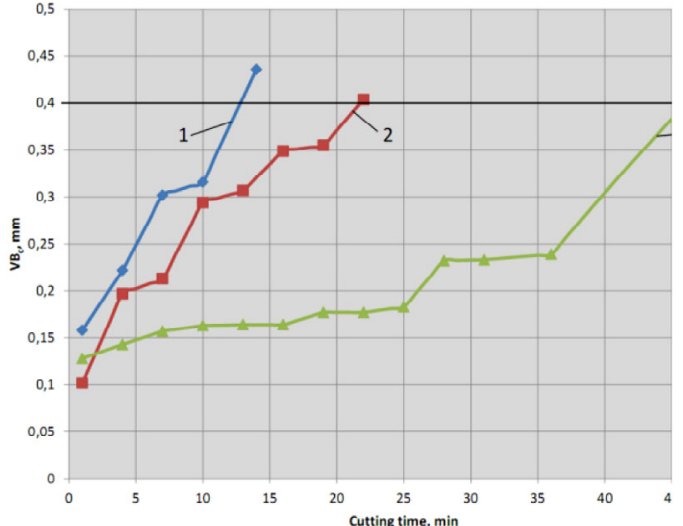

(b)

Fig. 3. Dependence of wear $V B$ on cutting time at dry turning of steel $\mathrm{C} 45$ at $a_{p}=1.0 \mathrm{~mm}, f=0.25 \mathrm{~mm} / \mathrm{rev}, v_{c}=200 \mathrm{~m} / \mathrm{min}$ (a), and $v_{c}=250 \mathrm{~m} / \mathrm{min}$ (b) 1: uncoated commercial carbide tool, 2: commercial carbide tool with TiN coating, and 3: carbide tool with developed comprehensive treatment.

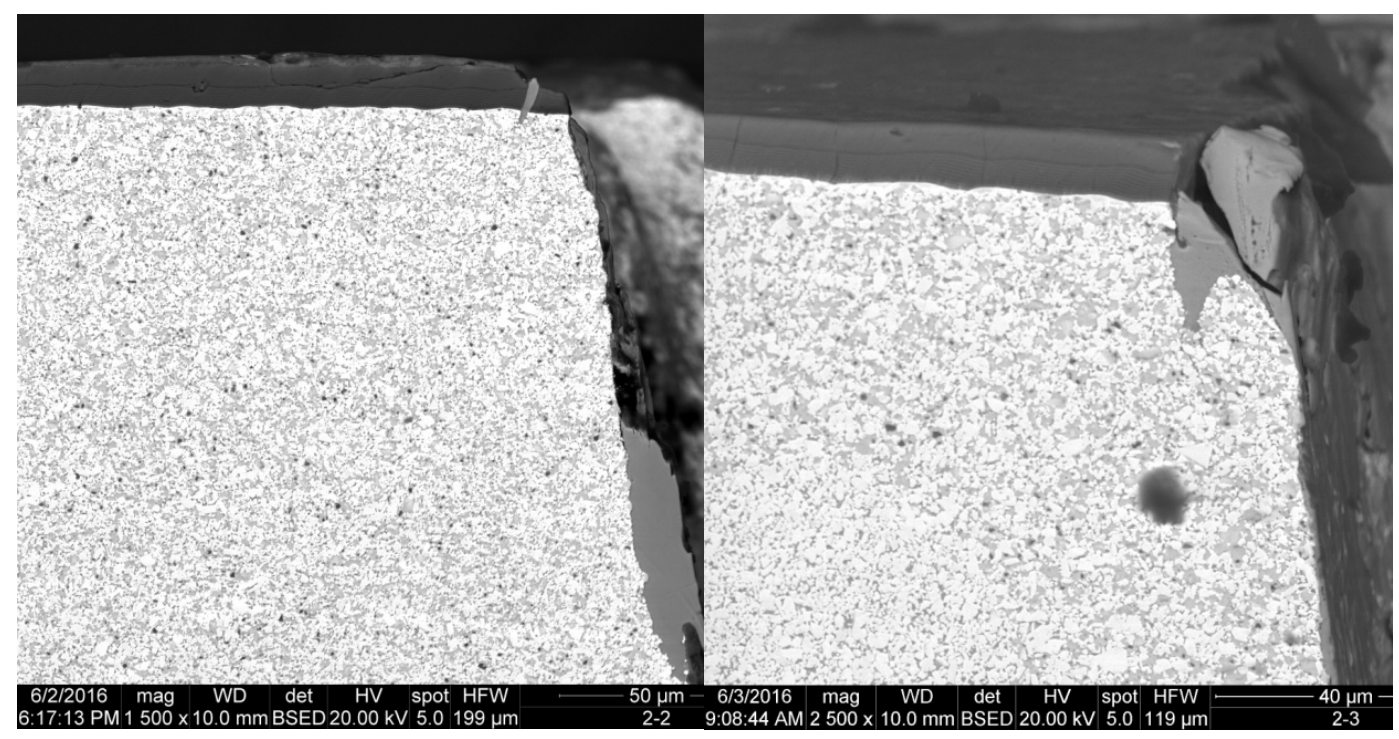

(a)

(b)

Fig. 4. Pattern of wear and failure of a carbide tool with the developed wear-resistant complex in dry turning of steel C45 at $a_{p}=1.0 \mathrm{~mm}, f=0.25 \mathrm{~mm} / \mathrm{rev}, v_{c}=200 \mathrm{~m} / \mathrm{min}$, after $46 \mathrm{~min}$ of cutting (a) and $v_{c}=250 \mathrm{~m} / \mathrm{min}$ after $41 \mathrm{~min}$ of cutting (b).

Figure 5 presents photomicrographs of the specifics of the wear and failure of the developed wear-resistant complex on the flank face of the tool. The tests have revealed almost complete destruction of the outer gradient layer of the complex while maintaining the inner layer with nanoscale sublayers. Figure 5 a reveals the presence of particles of the machined material adherent to the failure area of the carbide substrate, adjacent to the lower boundary of the wear-resistant complex. Meanwhile, a strong adhesive bond is observed between the wear-resistant complex and the carbide substrate.

Figure 6 presents the examples of deep penetration of the machined material into the system wear-resistant complex-substrate in the area of the transverse cracks. Meanwhile, a wedge-shaped extension of cracks occurs, and their width reaches $2.5-3 \mu \mathrm{m}$. However, no coating failure is observed in this area.

Following the analysis of the pattern of wear of the carbide tool with the developed wear-resistant complex, the following conclusions are proposed:

- Prevalent wear mechanisms of carbide tools with wearresistant complex are connected with adhesion-fatigue processes and brittle fracture of the system wearresistant complex-substrate. Practically no abrasive wear of the tool rake face is registered, and it appears relatively weakly on the tool flank face;

- There is a deep penetration of the machined material into the transverse cracks of the system coatingsubstrate;

- Tests have revealed relatively uniform, fragile failure of the outer gradient and intermediate nano-sublayers 


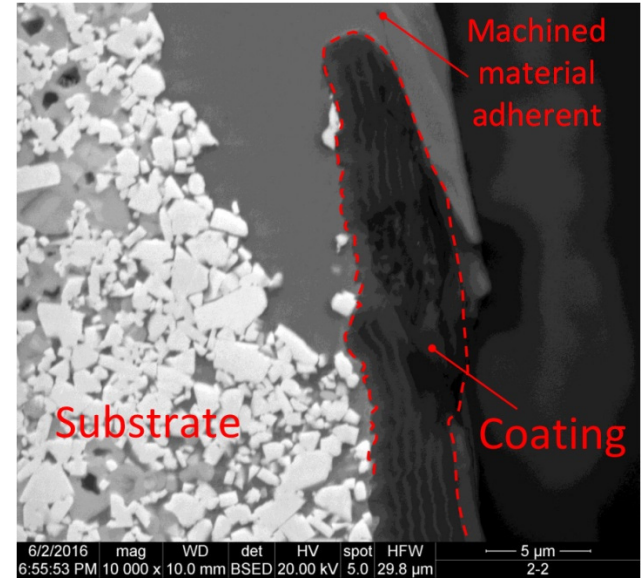

(a)

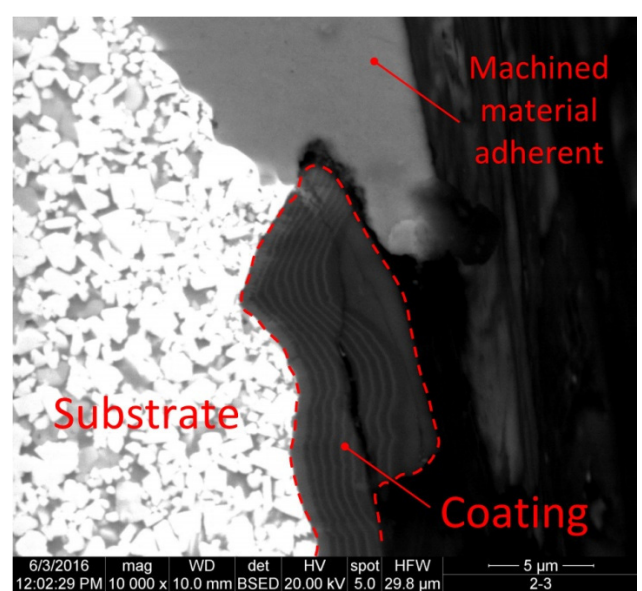

(b)

Fig. 5. Pattern of wear and failure of the wear-resistant complex on the flank face of the tool at dry turning of steel C45 at $\mathrm{a}_{p}=1.0 \mathrm{~mm}, f=0.25 \mathrm{~mm} / \mathrm{rev}, v_{c}=200 \mathrm{~m} / \mathrm{min}$, after $46 \mathrm{~min}$ of cutting (a) and $v_{c}=250 \mathrm{~m} / \mathrm{min}$ after $41 \mathrm{~min}$ of cutting (b).

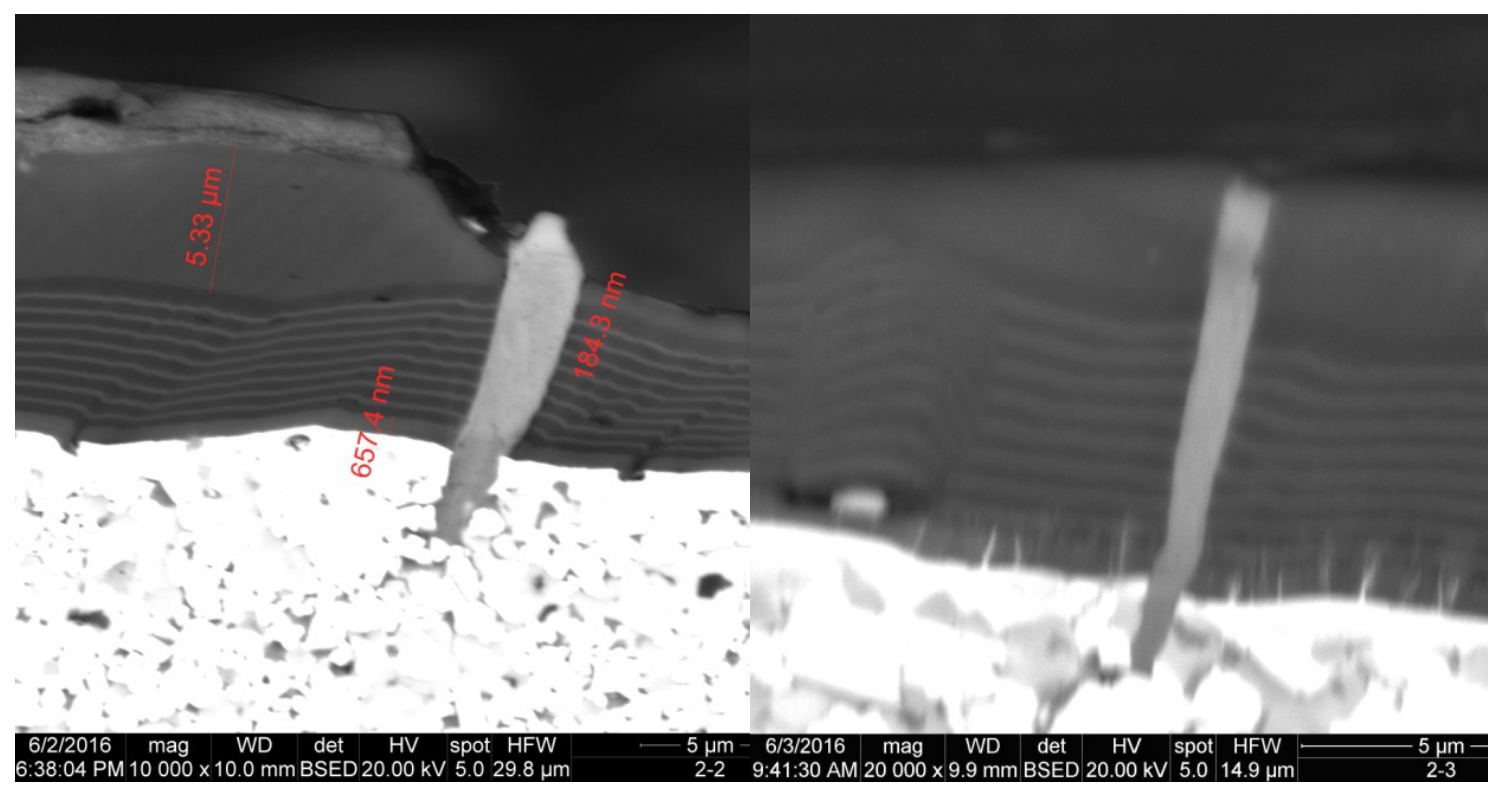

(a)

(b)

Fig. 6. Penetration of the machined material into the cracks of the system wear-resistant complex-substrate at dry turning of steel C45 at $a_{p}=1.0 \mathrm{~mm}, f=0.25 \mathrm{~mm} / \mathrm{rev}, v_{c}=200 \mathrm{~m} / \mathrm{min}$, after $46 \mathrm{~min}$ of cutting (a) and $v_{c}=250 \mathrm{~m} / \mathrm{min}$ after $41 \mathrm{~min}$ of cutting (b).

of the wear-resistant complex, while there was relatively intense failure of the outer gradient layer on the tool flank face, with sufficiently high resistance to failure of the intermediate layer of the wear-resistant complex.

\section{Conclusion}

The study of cutting properties and pattern of wear of the carbide substrate that was subjected to comprehensive surface treatment, including alloying with formation of hafnium carbide in the composition of composite carbide on the surface and the subsequent deposition of a complex multi-layered composite coating on the basis of the system (TiAl)N shows the following:

- Application of a comprehensive treatment on a carbide tool, including surface alloying by low-energy highcurrent electron beam, followed by the deposition of a multi-layered complex composite wear-resistant coating on the basis of the system $(\mathrm{TiAl}) \mathrm{N}$, can increase the life by 3-3.5 times in comparison with the life of the test carbide tool without coating and by two times in comparison with the life of a tool with the standard TiN coating.

- The specific feature of the wear mechanism of the carbide tool with the developed comprehensive treatment 
is a stable operation with minimal wear for 30-35 min, followed by sharp intensification of the mechanisms of brittle fracture of the system coating-substrate.

The studies suggest that the developed comprehensive surface treatment of the carbide substrate can significantly improve important performance properties of carbide tools, such as their life and reliability.

Acknowledgements. Financial support was provided by the Russian Ministry of Education and Science (project 9.1188.2014/K).

\section{References}

[1] S. Marinković, S. Stanković, Z. Rakočević, Effects of cemented carbide surface pretreatment in combustion flame chemical vapour deposition of diamond, Thin Solid Films 354 (1999) 118-128

[2] S. Stankovic, Z. Rakocevic, S. Marinkovic, Effects of the pretreatment of a cemented carbide surface on its properties and on the properties of diamond coatings deposited by oxygen-acetylene flame CVD, Diamond and Related Materials 8 (1999) 207-210

[3] B. Sahoo, A.K. Chattopadhyay, On effectiveness of various surface treatments on adhesion of HF-CVD diamond coating to tungsten carbide inserts, Diamond and Related Materials 11 (2002) 1660-1669

[4] J.M. Arroyo, A.E. Diniz, M.S.F. de Lima, Cemented carbide surface modifications using laser treatment and its effects on hard coating adhesion, Surf. Coat. Technol. 204 (2010) 2410-2416

[5] D. Neves, A.E. Diniz, M.S.F. Lima. Microstructural analyses and wear behavior of the cemented carbide tools after laser surface treatment and PVD coating, Appl. Surf. Sci. 282 (2013) 680-688

[6] M. Yang, et al.; Surface modification of WC-based cemented carbide by one-pot nonvapor deposition method derived $\mathrm{Al}_{2} \mathrm{O}_{3}$ coatings, Ceramics Int. 42 (2016) 1150911514

[7] K.D. Bouzakis, N. Michailidis, S. Hadjiyiannis, K. Efstathiou, E. Pavlidou, G. Erkens, S. Rambadt, I. Wirth, Improvement of PVD coated inserts cutting performance, through appropriate mechanical treatments of substrate and coating surface, Surf. Coat. Technol. 146-147 (2001) $443-450$

[8] C. Wang, C. Jiang, F. Cai, Y. Zhao, K. Zhu, Z. Chai, Effect of shot peening on the residual stresses and microstructure of tungsten cemented carbide, Mater. Design 95 (2016) 159-164

[9] F. Zhang, X. Zhu, M. Lei, Microstructure and properties of WC-Co cemented carbide irradiated by high-intensity pulsed ion beam, Jinshu Rechuli/Heat Treatment of Metals 41 (2016) 118-124
[10] A.A. Vereschaka, M.A. Volosova, S.N. Grigoriev, A.S. Vereschaka. Development of wear-resistant complex for high-speed steel tool when using process of combined cathodic vacuum arc deposition, Procedia CIRP 9 (2013) $8-12$

[11] A.A. Vereschaka, M.A. Volosova, A.D. Batako, A.S. Vereshchaka B.Y. Mokritskii, Development of wearresistant coatings compounds for high-speed steel tool using a combined cathodic vacuum arc deposition, Int. J. Adv. Manuf. Technol. 84 (2016) 1471-1482

[12] S.N. Grigor'ev, S.V. Fedorov, M.D. Pavlov, A.A. Okun'kova, Ye Min So, Complex surface modification of carbide tool by $\mathrm{Nb}$ plus $\mathrm{Hf}$ plus $\mathrm{Ti}$ alloying followed by hardfacing (Ti plus Al)N, J. Friction and Wear 34 (2013) $14-18$

[13] S.N. Grigoriev, A.A. Vereschaka, A.S. Vereschaka, A.A. Kutin, Cutting tools made of layered composite ceramics with nano-scale multilayered coatings, Procedia CIRP 1 (2012) 318-323

[14] A.A. Vereshchaka, A.S. Vereshchaka, O. Mgaloblishvili, M.N. Morgan, A.D. Batako, Nano-scale multilayeredcomposite coatings for the cutting tools, Int. J. Adv. Manuf. Technol. 72 (2014) 303-317

[15] A.O. Volkhonskii, A.A. Vereshchaka, I.V. Blinkov, A.S Vereshchaka, A.D. Batako, Filtered cathodic vacuum Arc deposition of nano-layered composite coatings for machining hard-to-cut materials, Int. J. Adv. Manuf. Technol. 84 (2016) 1647-1660

[16] A.A. Vereschaka, A.S. Vereschaka, A.D. Batako, O. Kh. Hojaev, B.Y. Mokritskii, Development and research of nanostructured multilayer composite coatings for tungsten-free carbides with extended area of technological applications, Int. J. Adv. Manuf. Technol. 87 (2016) 3449-3457

[17] A.A. Vereschaka, S.N. Grigoriev, A.S. Vereschaka, A. Yu. Popov, A. D. Batako, Nano-scale multilayered composite coatings for cutting tools operating under heavy cutting conditions, Procedia CIRP 14 (2014) 239-244

[18] A.B. Markov, et al., A PHTM-II facility for the surface alloying, Instruments and Experimental Techniques 54 (2011) 862-866

[19] T. Cselle, Nanostracturierte Schichten in der Werkstaff, Platit A. G. Warkzeugtagung, 2002

[20] P.J. Martin, O. Knotek, A. Scherey, et al., Handbook of Film Process Technology, London. IOP Publishing, 1995

[21] H. Holleck, Nanoskalige Schutyschichten fur hochbeanspruchte Bauteile. Holeck H., Leiste H., Ulrich A. NACHRICHEN - Forschungszentrum Karlsruhe Jahrg 31 (1999) 13-20 